\title{
Strategies to curb structural changes of lithium/transition metal oxide cathode materials \& the changes' effects on thermal \& cycling stability*
}

\author{
Xiqian $\mathrm{Yu}$ (禹习谦), Enyuan $\mathrm{Hu}$ (胡恩源), Seongmin Bak, \\ Yong-Ning Zhou(周永宁), and Xiao-Qing Yang(杨晓青) ${ }^{\dagger}$ \\ Chemistry Department, Brookhaven National Laboratory Upton, NY 11973, USA \\ (Received 14 May 2015; revised manuscript received 4 June 2015; published online 0 X 2015)
}

\begin{abstract}
Structural transformation behaviors of several typical oxide cathode materials during a heating process are reviewed in detail to provide in-depth understanding of the key factors governing the thermal stability of these materials. We also discuss applying the information about heat induced structural evolution in the study of electrochemically induced structural changes. All these discussions are expected to provide valuable insights for designing oxide cathode materials with significantly improved structural stability for safe, long-life lithium ion batteries, as the safety of lithium-ion batteries is a critical issue; it is widely accepted that the thermal instability of the cathodes is one of the most critical factors in thermal runaway and related safety problems.
\end{abstract}

Keywords: thermal stability, cathode, oxide, lithium ion batteries, safety

PACS: 82.47.Aa, 81.05.Je, 88.80.ff, 68.60.Dv

DOI: $10.1088 / 1674-1056 / 25 / 1 / 018205$

\section{Introduction}

Lithium-ion batteries (LiBs) have been leading candidates for vehicle applications due to their high energy density and high power capability. ${ }^{[1-4]}$ However, LiBs' safety issues have to be soundly addressed before large scale application. ${ }^{[5-7]}$ When an LiB experiences certain abusive situations, for example, shorting, the temperature of the battery can easily rise to the threshold of so-called "thermal runaway," in which the temperature rises very rapidly and is out of control. ${ }^{[6]} \mathrm{A}$ series of chemical reactions are triggered during such a process, and a considerable amount of heat can be released, possibly leading to fire or explosion. Each component in the battery, including anode, ${ }^{[8-10]}$ separator, ${ }^{[11-13]}$ electrolyte, ${ }^{[14-17]}$ and cathode, ${ }^{[18-23]}$ has its role to play in this process, and the role of the cathode has been proved to be particularly important. Only oxide systems as cathode materials are discussed in the present review. Readers interested in thermal stability of polyanion systems are encouraged to read references in the literature. ${ }^{[24-26]}$

Dahn $e t$ al. investigated the thermal stability of charged cathodes, including $\mathrm{Li}_{x} \mathrm{NiO}_{2}, \mathrm{Li}_{x} \mathrm{CoO}_{2}$, and $\lambda-\mathrm{MnO}_{2}$ (fully charged state of $\mathrm{LiMn}_{2} \mathrm{O}_{4}$ ), and found that they all release oxygen upon heating. ${ }^{[22]}$ Arai et al. conducted DSC measurements for charged $\mathrm{Li}_{x} \mathrm{NiO}_{2}$, ethylene carbonate (EC, a major component of the electrolyte), and the combination of these two, ${ }^{[23]}$ finding that heating the mixture of charged $\mathrm{Li}_{x} \mathrm{NiO}_{2}$ and EC is much more exothermic than heating either of them individually. This suggests that oxygen-release from a cathode is a key factor contributing to heat generation of the whole reaction. More advanced cathode materials normally contain multiple metal elements. Thermogravimetric and calorimetric studies of charged $\mathrm{Li}_{x} \mathrm{Ni}_{0.8} \mathrm{Co}_{0.15} \mathrm{Al}_{0.05} \mathrm{O}_{2}$ and charged $\mathrm{Li}_{x} \mathrm{Ni}_{1 / 3} \mathrm{Co}_{1 / 3} \mathrm{Mn}_{1 / 3} \mathrm{O}_{2}$ reveal that the former releases a larger amount of oxygen at a lower temperature than the latter. ${ }^{[27]}$ This correlates well with the fact that the former has much poorer safety characteristics in terms of a much greater amount of heat generated than the latter. ${ }^{[17]}$ Such a relationship between oxygen-release and safety characteristics is further confirmed in conditions closer to real battery operation by testing full-battery cells which include anode, separator, electrolyte, and cathode. ${ }^{[28]}$

When a charged cathode is heated, it tends to release oxygen. This is considerably detrimental because the released oxygen can react with the electrolyte in a highly exothermic way, significantly accelerating the elevation of temperature, and initiating further disastrous reactions. Therefore, designing cathode materials with suppressed oxygenrelease and/or increased onset temperature for oxygen-release would be an effective approach to such safety issues. While thermogravimetric, ${ }^{[9]}$ calorimetric, ${ }^{[23]}$ and computational studies ${ }^{[29]}$ have provided useful information like heat generation rate, chemical reaction kinetics, and so on; it is desirable to understand the roles of crystal and electronic

* Project supported by the U.S. Department of Energy, the Assistant Secretary for Energy Efficiency and Renewable Energy, Office of Vehicle Technologies (Grant No. DE-SC0012704).

†Corresponding author. E-mail: xyang@bnl.gov 
structural changes in the oxygen-release process, especially through in situ techniques. Hence, our group designed in situ $\mathrm{x}$-ray diffraction (XRD) and in situ x-ray absorption (XAS) techniques for studying the thermal stability of charged cathode materials. Here, we start with the experimental setup, then review results from our studies, ${ }^{[30-35]}$ and finally discuss the implications of these results for designing a stable cathode.

\section{Experimental techniques}

A technique combining in situ $\mathrm{x}$-ray diffraction with mass spectroscopy (MS) during heating was developed at the beamline 7B of the National Synchrotron Light Source (NSLS) facility by our group. ${ }^{[32]}$ This technique enables us to monitor crystal structure changes and oxygen-release simultaneously. In an in situ XRD-MS experiment illustrated in Fig. 1, a charged cathode is placed inside a tailored quartz tube where it can be heated at a controlled rate. The quartz tube is then connected to the MS. The whole system is purged with helium gas to provide an inert atmosphere. Once the charged cathode is heated, its structure is probed and recorded using a high intensity synchrotron beam as the $\mathrm{x}$-ray source in a timeresolved fashion, while the outlet gas information is recorded by the MS. A detailed description of the experimental setup can be obtained from our previous papers. ${ }^{[31-34]}$
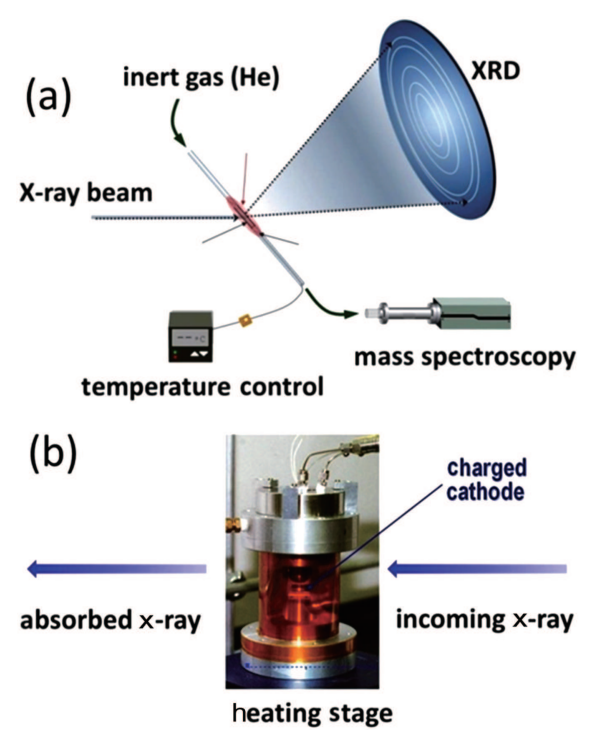

Fig. 1. (a) In situ XRD-MS and (b) in situ XAS experimental setup. The figure is adapted from Ref. [32].

Different contents and concentration ratios of metal elements in the cathode materials result in different thermal stability of the cathodes. This suggests that each element can play a unique role in stabilizing or destabilizing the structure. Commonly used metal elements for lithium-ion battery cathodes are mainly $3 \mathrm{~d}$ transition metal elements, which are very close to each other in the periodic table, making it difficult to distinguish them by XRD alone. Therefore, x-ray absorption is a very valuable tool in differentiating them. An XAS spectrum includes both the X-ray absorption near edge structure (XANES) and the extended $x$-ray absorption fine structure (EXAFS). These parts can provide information about the oxidation state, electronic structure, and local environment in an elemental selective way. An in situ XAS technique (shown in Fig. 2) has been employed by our group at beamline 18A of NSLS. In such experiments, a charged cathode is positioned in the center of a helium-purged chamber and exposed to the incoming x-ray with variable wavelength. As the sample is heated up, the absorption coefficient of each element as a function of incoming x-ray wavelength is recorded in a spectrum, which is to be analyzed later for electronic structural and local structural information. Combining the techniques of in situ XRD-MS and in situ XAS not only reveals the fundamental structural reason for oxygen-release, but also specifies the positive or negative role of each individual element in the stability of the cathode. This information provides valuable guidelines for the development of safer cathodes. In the following discussions, a review of our work on layer-structured $\mathrm{Li}_{x} \mathrm{Ni}_{0.8} \mathrm{Co}_{0.15} \mathrm{Al}_{0.05} \mathrm{O}_{2}, \quad \mathrm{Li}_{x} \mathrm{Ni}_{1 / 3} \mathrm{Co}_{1 / 3} \mathrm{Mn}_{1 / 3} \mathrm{O}_{2}$, and high voltage spinel $\mathrm{Li}_{x} \mathrm{Ni}_{0.5} \mathrm{Mn}_{1.5} \mathrm{O}_{4}$ is given, followed by discussions of the importance of these studies for cathode development. Note that all of the work discussed here was carried out on charged cathode samples in the absence of the electrolyte. Although adding the electrolyte to the sample could make the experimental conditions closer to real cell operation, it would reduce the comparability and reproducibility of the experiments. Since our main interest was in the fundamental understanding of the cathode materials, we excluded electrolyte from the setup of these experiments.

\section{Thermal stability studies of oxide cathode materials}

\subsection{Layered cathode materials}

Cubic-close-packed oxygen anions are layered, with lithium and transition metal occupying the octahedral sites in alternating layers. Among the layer-structured cathode materials, $\mathrm{LiNi}_{0.8} \mathrm{Co}_{0.15} \mathrm{Al}_{0.05} \mathrm{O}_{2}$ and $\mathrm{LiNi}_{1 / 3} \mathrm{Co}_{1 / 3} \mathrm{Mn}_{1 / 3} \mathrm{O}_{2}$ are important due to their useful electrochemical performance. However, despite the similarity of their crystal structures, their thermal stabilities differ quite a bit, suggesting the important role of the elemental content. Our group studied these two materials systematically, and some of the major results are reviewed here.

$\mathrm{Li}_{x} \mathrm{Ni}_{0.8} \mathrm{Co}_{0.15} \mathrm{Al}_{0.05} \mathrm{O}_{2}$ is highly favored for high energy applications. However, as suggested by its high nickel content, this material features poor thermal stability. The previous 
studies showed that this material releases oxygen at temperatures as low as around $200{ }^{\circ} \mathrm{C}$, lower than the oxygen-release onset of $\mathrm{Li}_{x} \mathrm{CoO}_{2}$ and $\lambda-\mathrm{Mn}_{2} \mathrm{O}_{4}$ (charged $\mathrm{LiMn}_{2} \mathrm{O}_{4}$ ). ${ }^{[22]}$ Structural investigations indicate that phase changes at high temperatures follow the "layered to spinel, and then to rock salt" path. ${ }^{[20,21]}$ What is fundamentally important but has not been studied in detail is the relationship between the oxygenrelease phenomena at the macroscopic level and the crystal structure changes at the atomic level, as well as the contribution of each individual element to these changes. In this review, through the results of in situ XRD-MS and in situ XAS studies, the correlations among crystal structure changes, transition metal migration, and oxygen-release will be thoroughly discussed, and more detailed information can be obtained from our previous publications. ${ }^{[31]}$
In situ XRD-MS results for the overcharged $\mathrm{Li}_{x} \mathrm{Ni}_{0.8} \mathrm{Co}_{0.15} \mathrm{Al}_{0.05} \mathrm{O}_{2}(x=0.33)$ are shown in Fig. 2. These results clearly indicate the close relationship between crystal structure changes and oxygen-release. First, the original layered structure (rhombohedral) changes into a $\mathrm{Co}_{3} \mathrm{O}_{4}$-type spinel structure at around $225^{\circ} \mathrm{C}$. This phase transition is quickly followed by a phase transition to rock salt, as can be seen in Fig. 2(a). The MS spectra clearly show that the amount of oxygen released from the spinel to rock salt step is considerably larger than that from the layered to spinel step, suggesting that this spinel to rock-salt step is more dangerous, so suppressing it or postponing it to higher temperatures would be beneficial for safer cathode materials. The cation migration path during these phase transitions is illustrated in Fig. 3.

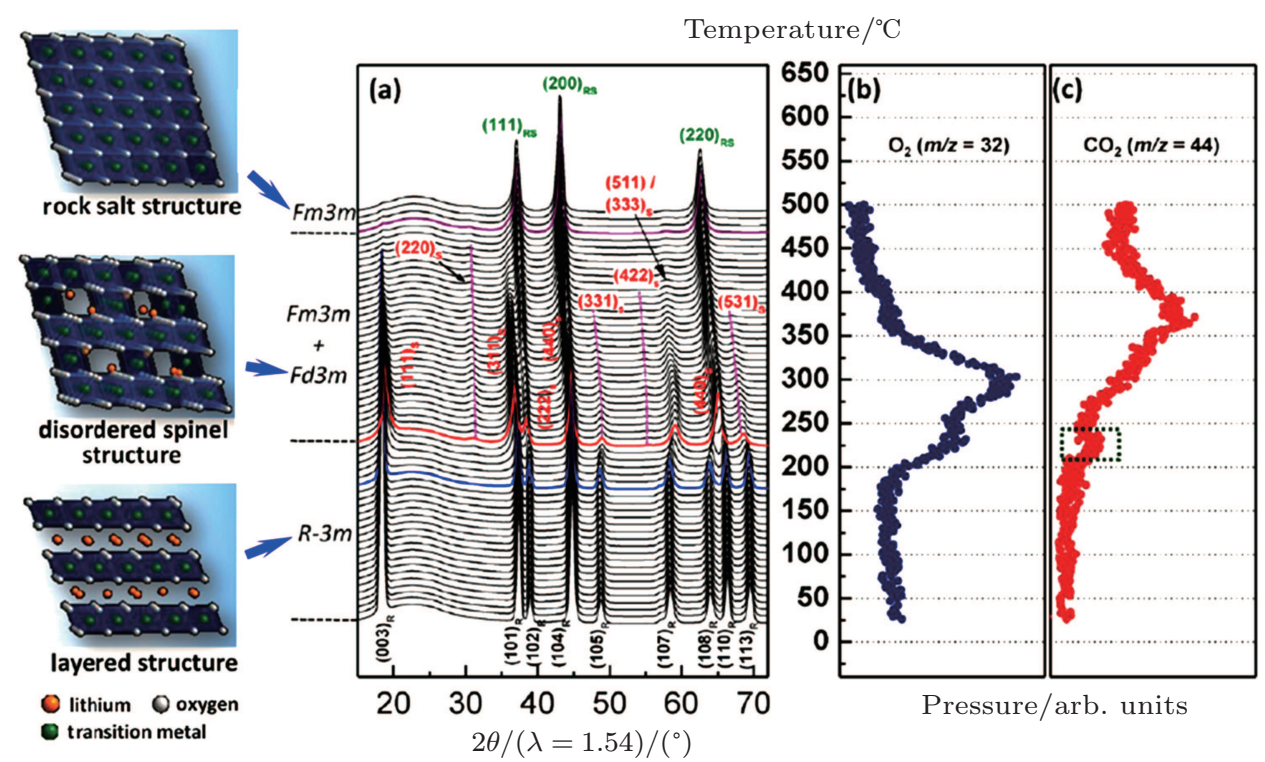

Fig. 2. (a) TR-XRD patterns and simultaneously measured mass spectra for (b) $\mathrm{O}_{2}$ and (c) $\mathrm{CO}_{2}$, released from $\mathrm{Li}_{0.33} \mathrm{Ni}_{0.8} \mathrm{Co}_{0.15} \mathrm{Al}_{0.05} \mathrm{O}_{2}$ during heating to $500{ }^{\circ} \mathrm{C}$. The formation of $\mathrm{CO}_{2}$ is associated with the oxidation of carbon (from either the PVDF binder or the conducting carbon in the charged electrode) by the released oxygen. ${ }^{[31]}$

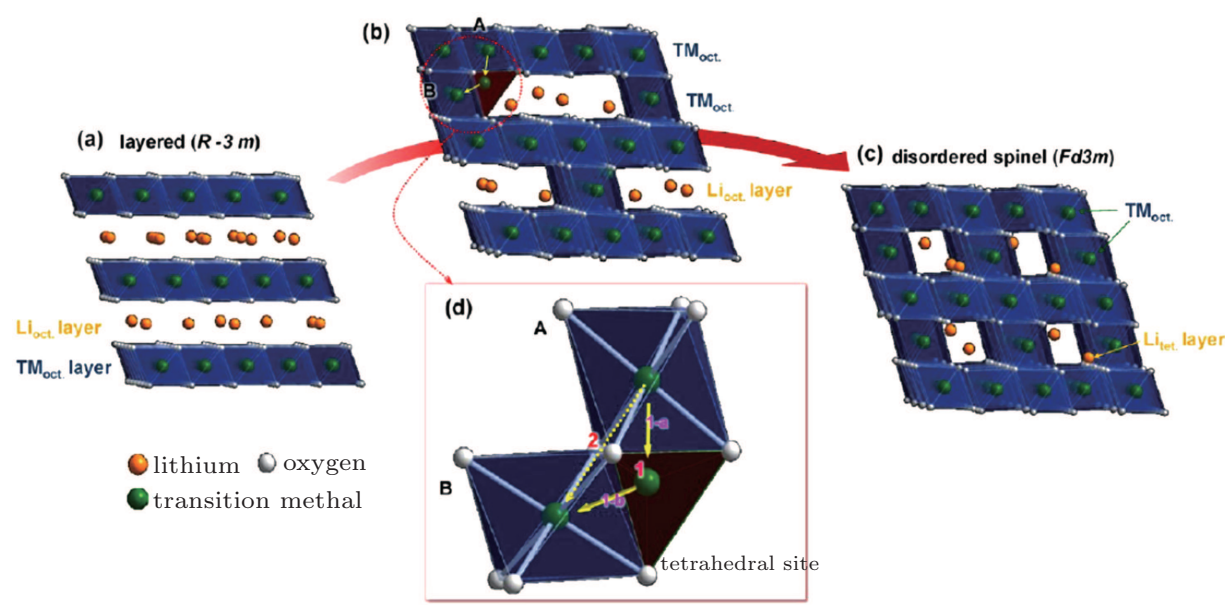

Fig. 3. Phase transition of $\mathrm{Li}_{x} \mathrm{Ni}_{0.8} \mathrm{Co}_{0.15} \mathrm{Al}_{0.05} \mathrm{O}_{2}$ charged cathode during heating: (a) layered structure, (b) cation migration during the phase transition from layered structure to disordered-spinel structure, (c) disordered spinel structure, and (d) cation migration path from octahedral A to octahedral B. Direct migration (path 2) between octahedral sites is energetically unfavorable, so transition metal ions prefer to travel through a neighboring tetrahedral site to the octahedral site (path 1). ${ }^{[31]}$ 

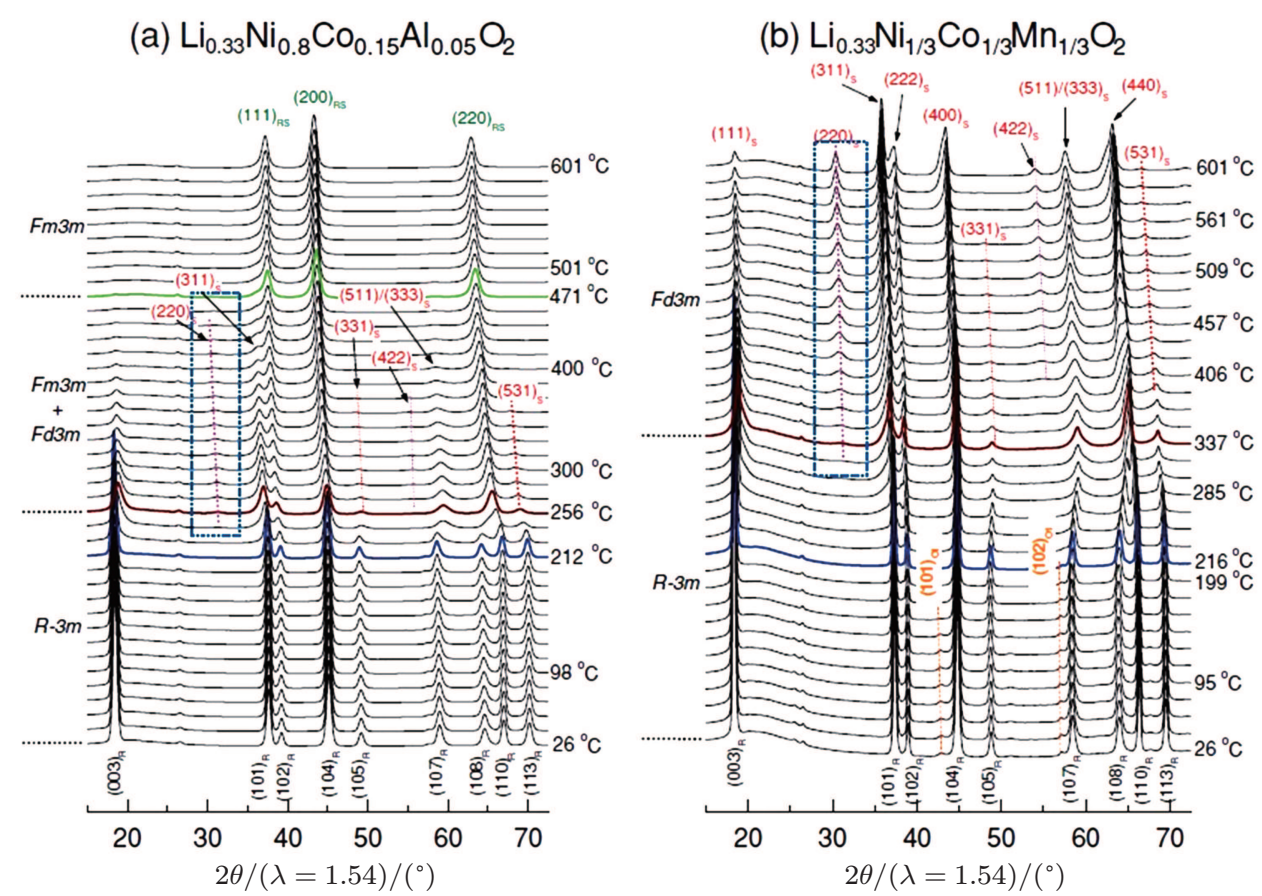

Fig. 4. Time-resolved (TR) XRD patterns of overcharged (a) $\mathrm{Li}_{0.33} \mathrm{Ni}_{0.8} \mathrm{Co}_{0.15} \mathrm{Al}_{0.05} \mathrm{O}_{2}$ and (b) $\mathrm{Li}_{0.33} \mathrm{Ni}_{1 / 3} \mathrm{Co}_{1 / 3} \mathrm{Mn}_{1 / 3} \mathrm{O}_{2}$ during heating to $600{ }^{\circ} \mathrm{C}$. The overcharged cathode samples sealed in quartz capillaries were heated from $25{ }^{\circ} \mathrm{C}$ to $600{ }^{\circ} \mathrm{C}$ for $4 \mathrm{~h}$ during the TR-XRD measurement (heating rate $=2.4^{\circ} \mathrm{C} \cdot \mathrm{min}^{-1}$ ). The subscripts $\mathrm{R}, \mathrm{S}$, and RS denote rhombohedral, spinel, and rock-salt structures, respectively. The subscript $\mathrm{O} 1$ represents $\mathrm{CdI}_{2}$-type $\mathrm{MO}_{2}(M=\mathrm{Ni}, \mathrm{Co} \mathrm{Mn})$ structure. ${ }^{[32]}$

$\mathrm{LiNi}_{1 / 3} \mathrm{Co}_{1 / 3} \mathrm{Mn}_{1 / 3} \mathrm{O}_{2}$ was proposed by Ohzuku et al. in $2001,{ }^{[36,37]}$ showing promising electrochemical performance and interesting structural features. This material demonstrated good capacity, good rate capability $\left(200 \mathrm{~mA} \cdot \mathrm{h} \cdot \mathrm{g}^{-1}\right.$ at $18.3 \mathrm{~mA} \cdot \mathrm{h} \cdot \mathrm{g}^{-1}$ and $150 \mathrm{~mA} \cdot \mathrm{h} \cdot \mathrm{g}^{-1}$ at $\left.1600 \mathrm{~mA} \cdot \mathrm{h} \cdot \mathrm{g}^{-1}\right),{ }^{[38]}$ and good thermal stability. ${ }^{[19]}$ Since then, various derivatives of this material have been explored, ${ }^{[39-41]}$ mainly by varying the nickel, cobalt, and manganese contents in a random or specified way (e.g., $\mathrm{LiNi}_{0.5-x} \mathrm{Co}_{2 x} \mathrm{Mn}_{0.5-x} \mathrm{O}_{2}$ ).

In our previous comparative studies, ${ }^{[32]}$ charged $\mathrm{Li}_{x} \mathrm{Ni}_{1 / 3} \mathrm{Co}_{1 / 3} \mathrm{Mn}_{1 / 3} \mathrm{O}_{2} \quad(x=0.33$, overcharged $\mathrm{NCM})$ was shown to be much more stable than charged $\mathrm{Li}_{x} \mathrm{Ni}_{0.8} \mathrm{Co}_{0.15} \mathrm{Al}_{0.05} \mathrm{O}_{2}(x=0.33$, overcharged NCA). At elevated temperature, the $\mathrm{NCM}$ releases considerably less oxygen than the NCA. Correspondingly, the NCM involves only the layered to spinel phase transition, with the spinel phase well preserved up to $500^{\circ} \mathrm{C}$. In contrast, the NCA involves both the layered to spinel and the spinel to rock-salt transitions, with the second step releasing a large amount of oxygen. Such differences in structural changes can be clearly seen in Fig. 4. An interesting question arising from this comparison is what factors made these differences, which can be answered through the following discussion of the in situ XAS results.

In our in situ XAS experiment, cobalt was identified to be the responsible element for the formation of the $\mathrm{Co}_{3} \mathrm{O}_{4}$-type spinel through migration to the tetrahedral sites for both $\mathrm{Li}_{0.33} \mathrm{Ni}_{0.8} \mathrm{Co}_{0.15} \mathrm{Al}_{0.05} \mathrm{O}_{2}$ and $\mathrm{Li}_{0.33} \mathrm{Ni}_{1 / 3} \mathrm{Co}_{1 / 3} \mathrm{Mn}_{1 / 3} \mathrm{O}_{2}$. However, in the NCM case, cobalt was observed to stay at a tetrahedral site upon further heating, stabilizing the structure as $\mathrm{Co}_{3} \mathrm{O}_{4}$-type spinel up to $500{ }^{\circ} \mathrm{C}$. This differs significantly from the behavior of cobalt in $\mathrm{Li}_{0.33} \mathrm{Ni}_{0.8} \mathrm{Co}_{0.15} \mathrm{Al}_{0.05} \mathrm{O}_{2}$, where cobalt ions migrate back to octahedral sites after spending a brief time at tetrahedral sites. Presumably due to the dilute concentration of cobalt, the $\mathrm{Co}_{3} \mathrm{O}_{4}$-type spinel structure in the $\mathrm{Li}_{0.33} \mathrm{Ni}_{0.8} \mathrm{Co}_{0.15} \mathrm{Al}_{0.05} \mathrm{O}_{2}$ 's case is relatively transient. Shortly after its formation, the rock-salt phase appears, initiating the step that involves significant oxygen release. The significant contrast in cobalt migration behavior is clearly seen in Fig. 5 , where the intensity of pre-edge feature A is a very good indicator for the tetrahedral occupation: the stronger the intensity of feature $\mathrm{A}$, the higher the tetrahedral occupation. It can be seen that for NCA, the intensity of pre-edge feature $\mathrm{A}$ increases from $25^{\circ} \mathrm{C}$ to $250^{\circ} \mathrm{C}$ and reaches the maximum at $250^{\circ} \mathrm{C}$, and then decreases from $250{ }^{\circ} \mathrm{C}$ to $500{ }^{\circ} \mathrm{C}$. In contrast, for NCM, the intensity of preedge feature A increases monotonously from $25^{\circ} \mathrm{C}$ to $500^{\circ} \mathrm{C}$. These results are in very good agreement with the phase transition behavior observed from XRD data in Fig. 4 and confirm that the prevalence of Co occupation at tetrahedral sites is the key factor for the better thermal stability of NCM vs. NCA.

This was further confirmed in studies of a series of charged $\mathrm{LiNi}_{x} \mathrm{Co}_{y} \mathrm{Mn}_{z} \mathrm{O}_{2}$ samples with various nickel, cobalt, and manganese contents, ${ }^{[33]}$ showing that higher cobalt content can suppress the oxygen-release more effectively, as seen in Fig. 6. However, this effectiveness can be realized only when the concentration of $\mathrm{Ni}$ is limited. As can be seen in 
Fig. 6, with the increase of the nickel concentration, the material becomes less and less stable at elevated temperatures. This trend can reach the point where cobalt is no longer able to stabilize the structure in a $\mathrm{Co}_{3} \mathrm{O}_{4}$-type spinel when the $\mathrm{Ni}$ concentration is above $50 \%$.

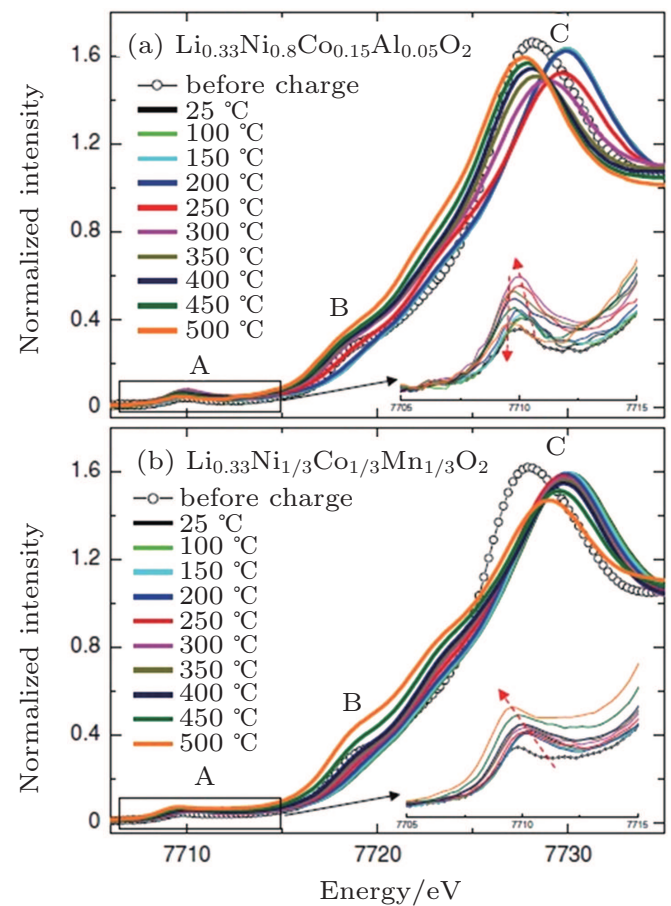

Fig. 5. Cobalt $K$-edge XANES spectra of overcharged (a) $\mathrm{Li}_{0.33} \mathrm{Ni}_{0.8} \mathrm{Co}_{0.15} \mathrm{Al}_{0.05} \mathrm{O}_{2}$ and (b) $\mathrm{Li}_{0.33} \mathrm{Ni}_{1 / 3} \mathrm{Co}_{1 / 3} \mathrm{Mn}_{1 / 3} \mathrm{O}_{2}$ electrodes during heating up to $500^{\circ} \mathrm{C}$. Insets show the detailed feature of pre-edge region A. ${ }^{[32]}$
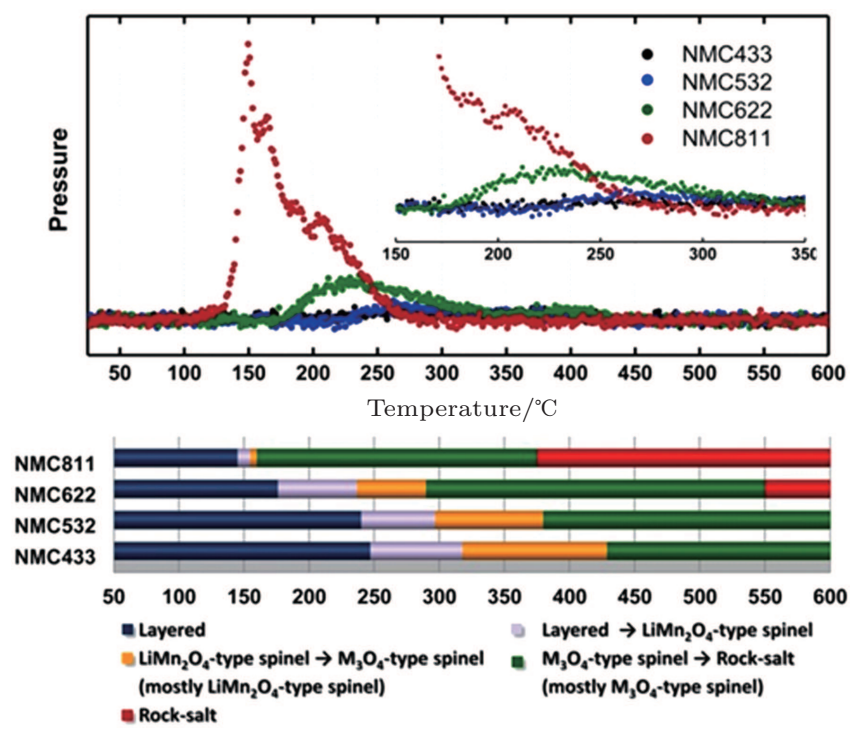

Fig. 6. Mass spectroscopy profiles for oxygen $\left(\mathrm{O}_{2}, m / z=32\right)$, collected simultaneously during measurement of TR-XRD, and the corresponding temperature regions of the phase transitions for NCM samples (lower panel). ${ }^{[33]}$

\subsection{High voltage spinel $\mathrm{LiNi}_{0.5} \mathrm{Mn}_{1.5} \mathrm{O}_{4}$}

High voltage spinel $\mathrm{LiNi}_{0.5} \mathrm{Mn}_{1.5} \mathrm{O}_{4}$ has attracted lots of attention in the past decade due to its high operating voltage (around $4.7 \mathrm{~V}$ ), which translates into high energy density. ${ }^{[42]}$ This material can either form the disordered phase with space group $F d \overline{3} m$ or the ordered phase with space group $\mathrm{P}_{3} 32$ depending on the annealing history. ${ }^{[43,44]}$ Electrochemical performance and phase transition routes during charging and discharging have been well characterized. ${ }^{[45-49]}$ In contrast, reports of thermal stability studies of this material have been rather limited except for some calorimetric measurements. ${ }^{[17,50,51]}$

The high voltage spinel can be viewed as a derivative of the conventional spinel $\mathrm{LiMn}_{2} \mathrm{O}_{4}$ with a quarter of the manganese replaced by nickel. After such substitution, the redox couple $\mathrm{Mn}^{3+} / \mathrm{Mn}^{4+}$ in $\mathrm{LiMn}_{2} \mathrm{O}_{4}$, which is around $4.0 \mathrm{~V}$, is replaced by the $\mathrm{Ni}^{2+} / \mathrm{Ni}^{3+}$ and $\mathrm{Ni}^{3+} / \mathrm{Ni}^{4+}$ redox couples in $\mathrm{LiNi}_{0.5} \mathrm{Mn}_{1.5} \mathrm{O}_{4}$, which are around $4.7 \mathrm{~V}$. This is beneficial for high energy density. However, thermal stability of the cathode material seriously deteriorates after nickel substitution. For fully charged $\mathrm{LiMn}_{2} \mathrm{O}_{4}$, which is also referred to as $\lambda-\mathrm{MnO}_{2}$, no oxygen-release is observed up to temperatures around $400{ }^{\circ} \mathrm{C} .{ }^{[22,52]}$ However, charged $\mathrm{LiNi}_{0.5} \mathrm{Mn}_{1.5} \mathrm{O}_{4}$ releases oxygen below $250{ }^{\circ} \mathrm{C}$, with the ordered phase having slightly better thermal stability than the disordered one, as can be seen from Fig. 7. ${ }^{[34]}$

This difference might be caused by the extra stability arising from cation ordering. In the $P 4_{3} 32$ phase, cations are arranged in an ordered way, releasing the strain and leading to a lower energy state. Such ordering is preserved in the charged sample and is believed to contribute to better thermal stability. In both cases, oxygen-release is accompanied by decomposition of the original crystal structure. The spinel framework is destroyed, decomposing into a mixture of $\mathrm{NiMnO}_{3}, \alpha-\mathrm{Mn}_{2} \mathrm{O}_{3}$, and $\mathrm{NiMn}_{2} \mathrm{O}_{4}$. The former two have completely different cation arrangements from the original spinel framework. The latter one, $\mathrm{NiMn}_{2} \mathrm{O}_{4}$, has the same spinel framework as delithiated $\mathrm{LiNi}_{0.5} \mathrm{Mn}_{1.5} \mathrm{O}_{4}$, providing the possibility that only transition metal cation migration is required to change $\mathrm{Li}_{x} \mathrm{Ni}_{0.5} \mathrm{Mn}_{1.5} \mathrm{O}_{4}(x=0)$ to $\mathrm{NiMn}_{2} \mathrm{O}_{4}$. In situ XAS studies reveal that nickel is quickly reduced, like in the $\mathrm{Li}_{x} \mathrm{NiO}_{2}$ 's case, and remains in the octahedral environment. Manganese, in contrast, migrates to the tetrahedral sites upon oxygen release, yielding the transition metal-in-tetrahedral site feature in $\mathrm{NiMn}_{2} \mathrm{O}_{4}$. Note that manganese has to be reduced from the original tetravalent state to a state close to the divalent state in order to enable such migration. Considering the large amount of manganese present in the sample, this implies that lots of reduction has to occur. In other words, considerable oxygen loss is inevitable in the phase transformation process. 

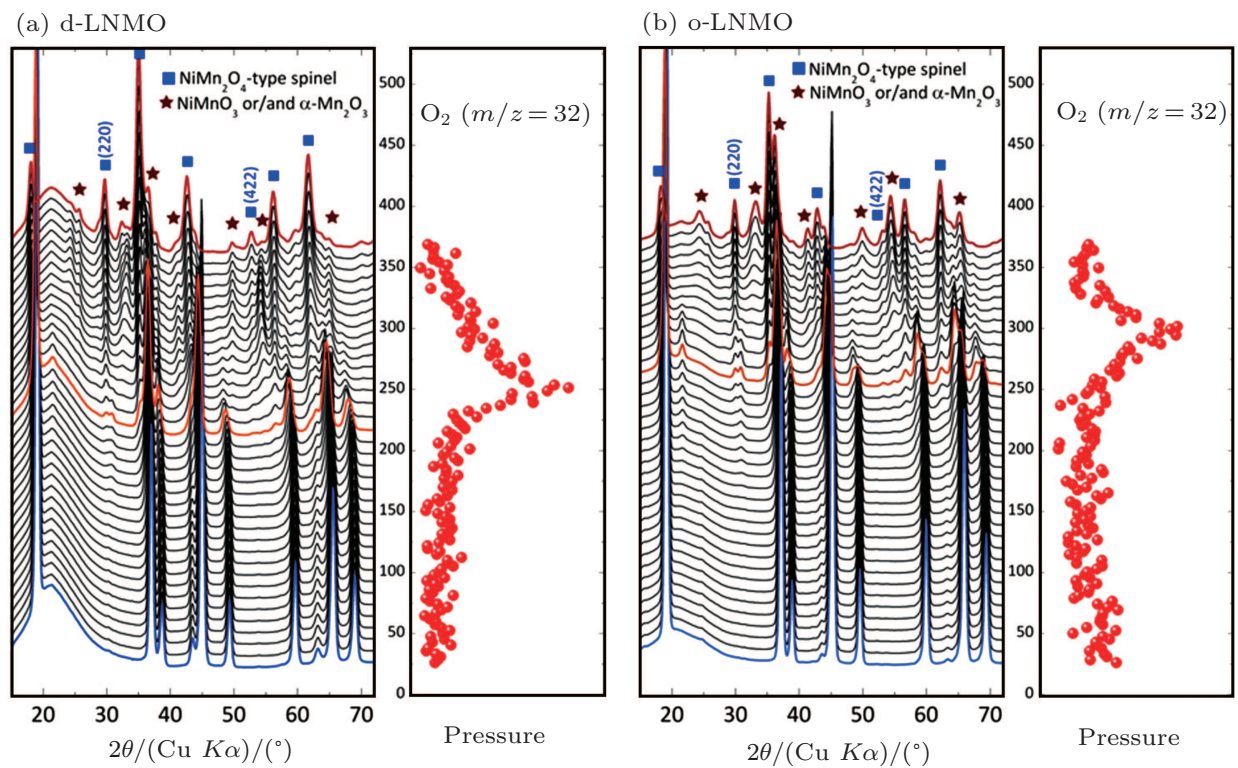

Fig. 7. In situ XRD patterns combined with simultaneously measured mass spectroscopy data that trace the release of gaseous oxygen of (a) disordered charged $\mathrm{LiNi}_{0.5} \mathrm{Mn}_{1.5} \mathrm{O}_{4}$ and (b) ordered charged $\mathrm{LiNi}_{0.5} \mathrm{Mn}_{1.5} \mathrm{O}_{4}$ during heating to $375{ }^{\circ} \mathrm{C}$. Left: in situ XRD patterns; right: profile of oxygen release. ${ }^{[34]}$

\section{Relationship between bulk crystal structure and thermal stability}

From the above examples, the oxygen-release at high temperatures is an inevitable event for charged oxide cathode materials. Such inevitability can be understood from a thermodynamic point of view. ${ }^{[29]}$ During the temperature elevation, the total amount of metal cations, including lithium and transition metals, is fixed but the amount of oxygen can vary. This implies that the phase diagram of multi-metal oxides with a fixed metal-to-metal ratio can provide the thermodynamic roadmap for the phase transition that occurs during temperature increase. (For instance, phase transitions of fully delithiated $\mathrm{LiNi}_{0.5} \mathrm{Mn}_{1.5} \mathrm{O}_{4}$ at high temperature can be well understood by referring to the phase diagram of $\mathrm{Ni} / \mathrm{Mn}$ oxide with a nickel-to-manganese ratio of 1:3.) Since, in these phase diagrams, the high temperature phase is normally low in oxygen compared to the low temperature phase, it is not surprising that oxygen-release can hardly be avoided for charged oxide cathode materials. In addition, the high oxygen partial pressures of oxides with highly oxidized cations such as $\mathrm{Ni}^{4+}$ and $\mathrm{Co}^{4+}$ imply that the cations all have a strong tendency to reduce. ${ }^{[53]}$ Therefore, both the phase diagram and the high oxidation state of transition metals in the charged cathode samples can explain the thermodynamic origins of the oxygen-release.

Since both structural change and transition metal reduction (and therefore oxygen-release) are thermodynamically driven, strategies for suppressing the oxygen-release leverage kinetic factors. In the charged oxide cathode materials that consist of $\mathrm{Ni}, \mathrm{Co}$, and $\mathrm{Mn}$, the ions of $\mathrm{Ni}, \mathrm{Co}$, and $\mathrm{Mn}$ are oxidized close to $\mathrm{Ni}^{4+}, \mathrm{Co}^{x+}(3.5<x<4)$, and $\mathrm{Mn}^{4+}$. ${ }^{[54]}$ Among these, $\mathrm{Ni}^{4+}$ is the easiest ion to reduce (to $\mathrm{Ni}^{2+}$ ), while $\mathrm{Mn}^{4+}$ the most difficult to reduced (to $\mathrm{Mn}^{2+}$ ). Therefore, the reduction of the $\mathrm{Ni}^{4+}$ ions takes place at the early stage of the heating process and generates a relatively large amount of oxygen gas. This is a critical step that governs the overall thermal instability of the material. To complete the structural transformation (such as layered to spinel and spinel to rock-salt) associated with the reduction of $\mathrm{Ni}^{4+}$, rearrangement of the $\mathrm{Ni}$ ions and other transition metal ions is necessary. This process requires migration of the transition metal ions from their original octahedral sites into either octahedral sites in neighboring layers or tetrahedral sites. ${ }^{[55]}$ Direct migration between octahedral sites is energetically unfavorable because the transition metal ions face strong columbic repulsion on the travel path. They prefer to travel through the nearest tetrahedral sites as shown in Fig. 4. Therefore, how easily the structure can transform into another form depends on how easily the transition metal ions can migrate from octahedral to tetrahedral sites, depending on the site preference of individual transition metal as well as the availability of the tetrahedral vacancy sites. The transition metal ions' preference for tetrahedral or octahedral site is determined by the $3 \mathrm{~d}$ electron configuration, which can be simply explained by crystal field theory (CFT). ${ }^{[56,57]}$ In the transition metal oxides, the $3 \mathrm{~d}$ orbitals of the transition metal ions split into different energies due to interaction with the surrounding oxygen atoms, and this process depends on the coordination environment, as shown in Fig. 8. The energy gain, called crystal field stabilization energy (CFSE), can be calculated on the basis of the $3 \mathrm{~d}$ electron configuration of the transition metal ions. By comparing the CFSE between octahedral and tetrahedral environments, the site preference of the transition metal ions can be estimated. ${ }^{[58]} \mathrm{Ni}^{4+}\left(3 \mathrm{~d}^{6}\right)$ and $\mathrm{Ni}^{3+}\left(3 \mathrm{~d}^{7}\right)$ have strong preference for octahedral site, while 
$\mathrm{Ni}^{2+}\left(3 \mathrm{~d}^{8}\right)$ has a less strong preference for octahedral site. Therefore, migration of the $\mathrm{Ni}$ ions between octahedral and tetrahedral sites requires their reduction into $\mathrm{Ni}^{2+}$. Therefore, in order to make the Ni migration-associated structural transformation occur, a relatively large amount of $\mathrm{Ni}^{4+}$ needs to be reduced to $\mathrm{Ni}^{2+}$ first, resulting in a large amount of oxygen released at an early stage of the heating process. For NCA, it can be considered that some of the $\mathrm{Ni}$ in $\mathrm{LiNiO}_{2}$ is replaced by $\mathrm{Co}$ and $\mathrm{Al}$. The reduction of the Co ions follows that of the $\mathrm{Ni}$ ions during the heating process, but $\mathrm{Co}^{3.67+}$ (charged state) needs less reduction $\left(\mathrm{Co}^{2.67+}\right.$ in $\left.\mathrm{Co}_{3} \mathrm{O}_{4}\right)$ to be able to migrate, so less oxygen gas is generated during this process. Meanwhile, the occupation of Co ions in tetrahedral sites will impede the migration of $\mathrm{Ni}$ ions, pushing the formation of the rock-salt phase to a higher temperature and spreading the oxygen-release in a wider temperature range compared with pure $\mathrm{LiNiO}_{2}$. Due to the high nickel content and low cobalt and alumina contents in NCA material, the rock-salt phase still forms at a relatively low temperature and a considerable amount of oxygen is released, because there are too few Co ions to occupy the tetrahedral sites and stabilize the structure. For NCM series materials, the onset oxygen-release temperature increases with increasing cobalt content, but decreases with increasing nickel content. The amount of $\mathrm{Co}$ ions in $\mathrm{LiNi}_{0.5} \mathrm{Co}_{0.2} \mathrm{Mn}_{0.3} \mathrm{O}_{2}$ is sufficient to stabilize the overall structure at the spinel phase, so no further reduction of manganese is necessary during the entire heating process. Therefore, the onset temperature of oxygen-release is delayed and less oxygen gas is released in comparison with NCA. In contrast, the $\mathrm{Mn}^{4+}$ ions need to be reduced for migration in high voltage spinel $\mathrm{LiNi}_{0.5} \mathrm{Mn}_{1.5} \mathrm{O}_{4}$ during the heating process. Although $\mathrm{Mn}^{4+}$ needs only to be reduced to $\mathrm{Mn}^{3+}$ for migration (through a charge disproportionation reaction $\mathrm{Mn}_{\mathrm{oct}}^{3+}=\mathrm{Mn}_{\text {tet }}^{2+}+\mathrm{Mn}_{\mathrm{oct}}^{4+} ; \mathrm{Mn}^{2+}$ prefers tetrahedral sites), ${ }^{[55]}$ the relatively large amount of $\mathrm{Mn}$ ion reduction still generates a large amount of oxygen, causing thermal instability.

In summary, reduction of the transition metal ions, accompanied by oxygen-release and structural transformation, is unavoidable during the heating process in most cases. Since the structural transformation requires migration of the transition metal ions through tetrahedral sites, cations that need no or less reduction to become mobile and prefer to occupy tetrahedral sites favor overall thermal stability of the cathode materials. Such cations stabilize the structure at a certain phase at an early stage of the heating process, delaying further structural transformation to higher temperatures. Less oxygen gas will be generated, and oxygen-release will be spread across a wider temperature range. For example, some fixed valence cations $\left(\mathrm{Mg}^{2+}, \mathrm{Al}^{3+}, \mathrm{Zn}^{2+}\right.$, etc. $)$, migrate easily to tetrahedral sites during the heating process and have been proven to improve thermal stability of transition metal oxide cathode ma- terials. However, these cations are electrochemically inactive, so a considerable amount of substitution will come at the expense of the capacity of the materials. Substitution of specific electrochemically active elements, such as $\mathrm{Co}$ and $\mathrm{Fe}$, could be a better choice to enhance the thermal stability of oxide materials. This has been demonstrated in the above discussion of the NCA and NCM series materials and will be further studied in Fe-substituted high voltage spinel in our future work. ${ }^{[59]}$

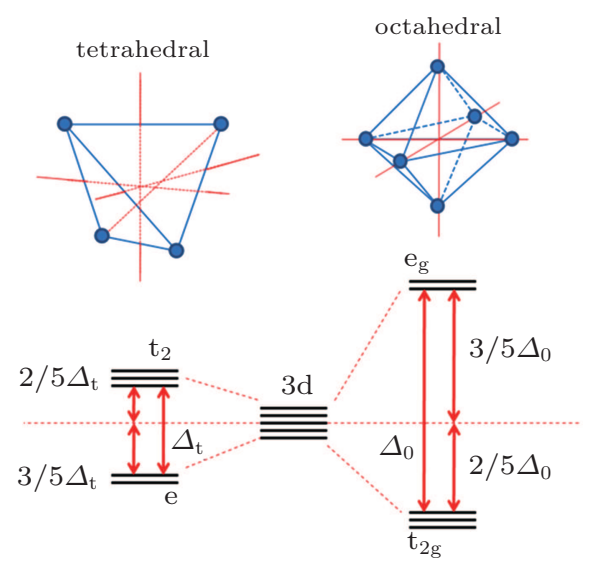

Fig. 8. Crystal field splitting of the transition metal $3 d$ orbital in tetrahedral and octahedral environments. The tetrahedral crystal field splitting energy $\Delta_{\mathrm{t}}$ is smaller than the octahedral crystal field splitting energy $\Delta_{0}$ and yields the relationship $\Delta_{\mathrm{t}}=4 / 9 \Delta_{0}$. The site preference of the transition metal ion can be predicted by crystal field stabilization energy (CFSE) calculated based on its electron configuration.

\section{Relationship between location dependent structural changes and thermal stability}

The time-resolved XRD and XAS studies reveal that the structure and chemical composition of the materials play important roles in determining their structural stability during heating. These XRD and XAS data were collected by averaging a sample area on $\mathrm{mm}$ scale, therefore only reflecting the average structural changes. In fact, the structural transformation during the heating process involves nucleation and propagation of new structure, which takes place at the atomic scale. Exploring the structural changes during heating with high spatial resolution and precise awareness of location would provide valuable insights for understanding the overall thermal stability of the materials. High resolution transmission electron microscopy (HRTEM) is a suitable tool for probing the local details of the phase transformation during heating, because it offers both local structure and chemical information. ${ }^{60,61]}$

In our work, in situ TEM has been employed to study the structural origin of the overcharge-induced thermal instability of two cathode oxide materials that exhibit significant differences in thermal stability, NCA and NCM. ${ }^{[30]}$ Detailed TEM analysis reveals that overcharged NCA and NCM particles both have complex core-shell-surface structures, which cannot be detected by XRD. For overcharged NCA, HRTEM imaging reveals three structures in the scale of tens of nanometers, 
as shown in Fig. 9: rhombohedral (located in the core of the particle), spinel (the shell near the surface), and rock-salt (at the surface layer of the particle). In contrast, the overcharged NCM particles have a core-shell-surface structure with $\mathrm{O} 1$ ( $\mathrm{CdI}_{2}$-type) on the surface, the spinel phase in the shell, and the rhombohedral phase in the core. In situ TEM experiments for NCA during heating reveal rapid growth of the rock-salt phase along with oxygen-release, while for NCM, slow structural transformation into the spinel phase was observed. These observations are in good agreement with the time-resolved XRD results. More importantly, the TEM results indicate that the difference in surface structures of overcharged NCA and NCM particles before heating is responsible for their different thermal decomposition behaviors. The rock-salt phase on the surface of overcharged NCA acts as a seed to accelerate the phase transformation to spinel and rock-salt phases during heating. The rapid growth of the rock-salt structure, accompanied by a release of a large amount of oxygen gas, causes thermal instability in NCA. In contrast, the $\mathrm{CdI}_{2}$-type surface structure on overcharged NCM particles protects the material from losing oxygen during the heating process. Therefore, it postpones the oxygen-release reaction to a higher temperature, resulting in better thermal stability. This research reveals that the surface structure of the materials will strongly influence the

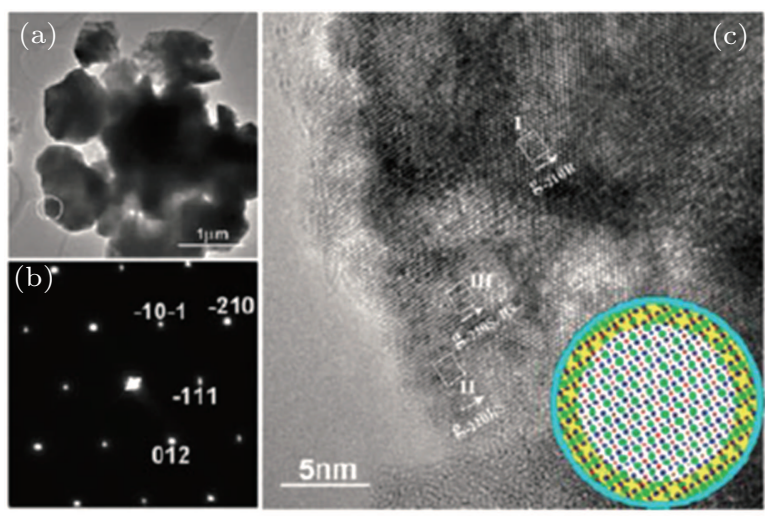

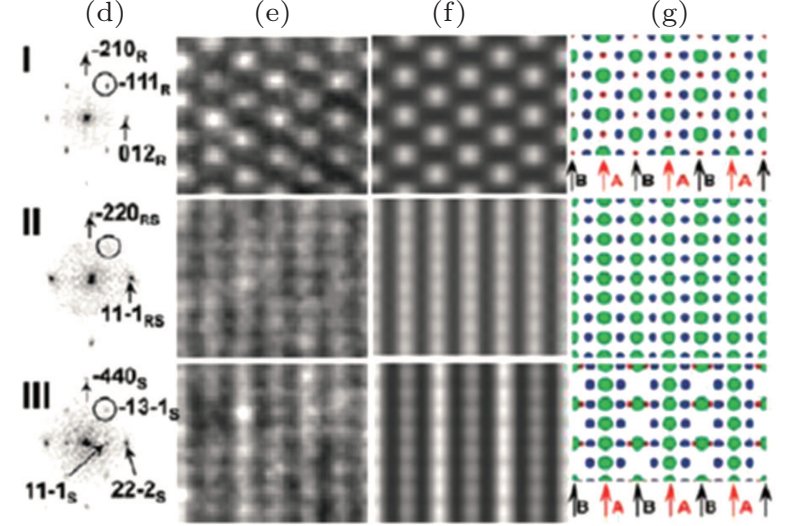

Fig. 9. HRTEM images, selected area electron-diffraction pattern (SAEDP) and simulated structure of overcharged $\mathrm{Li}_{x} \mathrm{Ni}_{0.8} \mathrm{Co}_{0.15} \mathrm{O}_{2}$. Three phases, rhombohedral (in the core), spinel (in the shell), and rocksalt (on the surface), have been identified on the charged particle in the same image. ${ }^{[30]}$ phase transformation kinetics during heating. Therefore, surface modification is another effective way to improve the thermal stability of the materials. For example, a concentrationgradient layered oxide material, ${ }^{[62]}$ with a surface rich in manganese and bulk rich in nickel, shows better thermal stability than pure high-nickel-content layered oxide materials (such as NCA), because the decomposition of the manganese rich surface structure forms a $\mathrm{CdI}_{2}$-type $\mathrm{MnO}_{2}$ structure, which suppresses the oxygen-release associated with the phase transformation for the entire material.

\section{Applying structural information obtained from thermal stability to cycling stability}

Note that structural decomposition has been found on the surface of the overcharged particle at room temperature, as mentioned above. For $\mathrm{Li}_{x} \mathrm{Ni}_{0.8} \mathrm{Co}_{0.15} \mathrm{O}_{2}(x<0.15)$, the overcharge-induced new phase propagates from the surface to the bulk of particles, following the process of rhombohedral to spinel to rock-salt. This resembles the phase transformation sequence observed in heating. For most transition metal oxide cathode materials, the structural decomposition, accompanied by oxygen-release, often occurs in a deeply delithiated state (high voltage charging). This kind of structural transformation normally proceeds mildly and starts from the surface of the material, making it difficult to track by bulk characterization tools such as XRD. However, understanding the origin of the structural decomposition is vital to the development of stable cathode materials, because these subtle irreversible structural changes will accumulate during electrochemical cycling and result in capacity fading during long-term cycling. As revealed, the surface structure evolution during electrochemical cycling is similar to the bulk structure evolution during heating. The knowledge gained from thermal studies might provide valuable information for predicting the structural evolution of the material over long-term electrochemical cycling. This is understandable, because the metastable highly delithiated (or overcharged) structure tends to transform into a stable structure during electrochemical cycling, and heating accelerates this transformation. Therefore, approaches that are effective to improve the thermal stability of the material could also be applied to enhance its structural stability during electrochemical cycling. Recent research on lithium rich manganese based layered oxide cathode materials demonstrates this point. The lithium rich materials attract lots of interest nowadays, because they can deliver exceptionally high reversible capacity, exceeding $250 \mathrm{~mA} \cdot \mathrm{h} \cdot \mathrm{g}^{-1}$ between $4.8 \mathrm{~V}$ and 2 V. ${ }^{[54,63,64]}$ Despite delivering high capacity, lithium-rich materials exhibit several practical shortcomings, such as continuous fading of both capacity and voltage during electrochemical cycling. ${ }^{[65-67]}$ The scientific community has made substantial efforts to understand these phenomena. The layered-to-spinel 
structural transformation, accompanied by oxygen release, is found to occur on the surface of the material during charging at high voltage. This phase transformation behavior, which is considered to be one of the primary factors responsible for the voltage and capacity fading of lithium-rich layered material, is analogous to its thermal decomposition behavior at an early stage of heating $\left(<250{ }^{\circ} \mathrm{C}\right.$, results will be reported in our future work). ${ }^{[68,69]}$ Surface coating, ${ }^{[70]}$ an effective approach to improve thermal stability for most oxide materials, can also be applied to suppress the oxygen-release of lithium-rich materials during high voltage charging and to retard the structural transformation into the spinel phase. Strategies of substituting specific cations that are able to inhibit the thermal decomposition of the material during heating ${ }^{[67]}$ can also be applied to alleviate the structural transformation of lithium-rich layered material during electrochemical cycling. Bear in mind that the structural evolution revealed by thermal studies is more significant and easier to identify than the subtle structural changes occurring during each electrochemical cycle. Thermal studies may provide an alternative way to understand the structural origin of the cyclic instability of the materials and offer useful guidance in developing more structurally stable electrode materials for lithium ion batteries.

\section{Conclusion}

The structure changes of several typical charged oxide cathode materials (NCA, NCM, and high voltage spinel) during a heating process, at both bulk and atomic levels, are reviewed in a comparative way, based on results obtained from in situ time-resolved XRD and MS, in situ XAS, and in situ TEM experiments. It has been found that the structural transformation (or decomposition) together with oxygen-release is inevitable for charged oxide cathode materials during the heating process. Several approaches are proposed to improve the thermal stability of oxide cathode materials: (i) substituting specific cations that require only slight reduction to migrate into tetrahedral sites of the oxygen framework at early stages of heating is an effective way to improve the intrinsic thermal stability of the material. On one hand, the slight reduction of these cations will generate only a small amount of oxygen. On the other hand, the occupation of these ions in the tetrahedral sites will impede the migration of other transition metal ions that are required for further structural transformation, so the onset temperature of structural transformation will be pushed higher. (ii) Surface modification that can prevent the structure decomposition from the surface is another effective approach to improve the thermal stability of the cathode materials. In addition, it has been revealed that the structural transformation of the oxide cathode materials, due to high voltage charging during electrochemical cycling, is similar to their structural transformation observed during heating. Therefore, the information obtained from thermal studies may also provide valuable insights for developing electrode materials with better cycle stability.

\section{Acknowledgement}

The authors acknowledge the technical support of scientists at beamline X7B, X18A at NSLS (BNL) and beamline 12BM-B and 17BM-B at APS (ANL).

\section{References}

[1] Tarascon J M and Armand M 2001 Nature 414359

[2] Goodenough J B and Kim Y 2010 Chem. Mater. 22587

[3] Goodenough J B 2013 Acc. Chem. Res. 461053

[4] Goodenough J B and Park K S 2013 J. Am. Chem. Soc. 1351167

[5] Balakrishnan P G, Ramesh R and Kumar T P 2006 J. Power Sources 155401

[6] Wang Q S, Ping P, Zhao X J, Chu G Q, Sun J H and Chen C H 2012 J. Power Sources 208210

[7] Hammami A, Raymond N and Armand M 2003 Nature 424635

[8] Yang H, Bang H, Amine K and Prakash J 2005 J. Electrochem. Soc. 152 A73

[9] Richard M N and Dahn J R 1999 J. Electrochem. Soc. 1462068

[10] Richard M N and Dahn J R 1999 J. Electrochem. Soc. 1462078

[11] Cho T H, Tanaka M, Onishi H, Kondo Y, Nakamura T, Yamazaki H, Tanase S and Sakai T 2008 J. Power Sources 181155

[12] Huang X S 2011 J. Solid State Electrochem. 15649

[13] Arora P and Zhang Z M 2004 Chem. Rev. 1044419

[14] Sloop S E, Pugh J K, Wang S, Kerr J B and Kinoshita K 2001 Electrochem. Solid-State Lett. 4 A42

[15] Aurbach D, Talyosef Y, Markovsky B, Markevich E, Zinigrad E, Asraf L, Gnanaraj J S and Kim H 2004 J. Electrochim. Acta 50247

[16] Sun X, Lee H S, Yang X Q and McBreen J 2002 Electrochem. SolidState Lett. 5 A248

[17] Xiang H F, Wang H, Chen C H, Ge X W, Guo S, Sun J H and Hu W Q 2009 J. Power Sources 191575

[18] Baba Y, Okada S and Yamaki J I 2002 Solid State Ionics 148311

[19] MacNeil D, Lu Z, Chen Z and Dahn J R 2002 J. Power Sources 1088

[20] Guilmard M, Croguennec L and Delmas C 2003 Chem. Mater. 154484

[21] Guilmard M, Croguennec L, Denux D and Delmas C 2003 Chem. Mater. 154476

[22] Dahn J, Fuller E, Obrovac M and Von Sacken U 1994 Solid State Ionics 69265

[23] Arai H, Okada S, Sakurai Y and Yamaki J I 1998 Solid State Ionics 109 295

[24] Ong S P, Jain A, Hautier G, Kang B and Ceder G 2010 Electrochem. Commun. 12427

[25] Li G H, Azuma H and Tohda M 2002 Electrochem. Solid-State Lett. 5 A135

[26] Andersson A S, Thomas J O, Kalska B and Haggstrom L 2000 Electrochem. Solid-State Lett. 366

[27] Belharouak I, Lu W Q, Vissers D and Amine K 2006 Electrochem. Commun. 8329

[28] Golubkov A W, Fuchs D, Wagner J, Wiltsche H, Stangl C, Fauler G, Voitic G, Thaler A and Hacker V 2014 Rsc Adv. 43633

[29] Wang L, Maxisch T and Ceder G 2007 Chem. Mater. 19543

[30] Wu L J, Nam K W, Wang X J, Zhou Y, Zheng J C, Yang X Q and Zhu Y 2011 Chem. Mater. 233953

[31] Bak S M, Nam K W, Chang W, Yu X, Hu E, Hwang S, Stach E A, Kim K B, Chung K Y and Yang X Q 2013 Chem. Mater. 25337

[32] Nam K W, Bak S M, Hu E, Yu X, Zhou Y, Wang X, Wu L, Zhu Y, Chung K Y and Yang X Q 2013 Adv. Funct. Mater. 231047

[33] Bak S M, Hu E, Zhou Y, Yu X, Senanayake S D, Cho S J, Kim K B, Chung K Y, Yang X Q and Nam K W 2014 ACS Appl. Mater. Interface 622594

[34] Hu E, Bak S M, Liu J, Yu X, Zhou Y, Ehrlich S N, Yang X Q and Nam K W 2014 Chem. Mater. 261108

[35] Hu E, Bak S M, Senanayake S D, Yang X Q, Nam K W, Zhang L and Shao M 2015 J. Power Sources 277193 
[36] Yabuuchi N and Ohzuku T 2003 J. Power Sources 119171

[37] Ohzuku T and Makimura Y 2001 Chem. Lett. 64230

[38] Ellis B L, Lee K T and Nazar L F 2010 Chem. Mater. 22691

[39] Kim G H, Myung S T, Bang H J, Prakash J and Sun Y K 2004 Electrochem. Solid-State Lett. 7 A477

[40] Ngala J K, Chernova N A, Ma M, Mamak M, Zavalij P Y and Whittingham M S 2004 J. Mater. Chem. 14214

[41] Oh S W, Park S H, Park C W and Sun Y K 2004 Solid State Ionics 171 167

[42] Zhong Q M, Bonakdarpour A, Zhang M J, Gao Y and Dahn J R 1997 J. Electrochem. Soc. 144205

[43] Xiao J, Chen X L, Sushko P V, SushkoML, Kovarik L, Feng J J, Deng Z Q, Zheng J M, Graff G L, Nie Z M, Choi DW, Liu J, Zhang J G and Whittingham M S 2012 Adv. Mater. 242109

[44] Kunduraci M, Al-Sharab J F and Amatucci G G 2006 Chem. Mater. 18 3585

[45] Kunduraci M and Amatucci G G 2008 Electrochim. Acta 534193

[46] Patoux S, Daniel L, Bourbon C, Lignier H, Pagano C, Le Cras F, Jouanneau S and Martinet S 2009 J. Power Sources 189344

[47] Shin D W, Bridges C A, Huq A, Paranthaman M P and Manthiram A. 2012 Chem. Mater. 243720

[48] Kim J H, Myung S T, Yoon C S, Kang S G and Sun Y K 2004 Chem. Mater. 16906

[49] Ariyoshi K, Iwakoshi Y, Nakayama N and Ohzuku T 2004 J. Electrochem. Soc. 151 A296

[50] Bhaskar A, Gruner W, Mikhailova D and Ehrenberg H 2013 Rsc Adv. 3 5909

[51] Patoux S, Sannier L, Lignier H, Reynier Y, Bourbon C, Jouanneau S, Le Cras F and Martinet S 2008 Electrochim. Acta $\mathbf{5 3} 4137$

[52] Tarascon J M and Guyomard D 1993 Electrochim. Acta 381221

[53] Whittingham M S 2004 Chem. Rev. 1044271
[54] Yu X, Lyu Y, Gu L, Wu H, Bak S M, Zhou Y, Amine K, Ehrlich S N, Li H, Nam K W and Yang X Q 2014 Adv. Energy Mater. 41300950

[55] Reed J and Ceder G 2004 Chem. Rev. 410

[56] Figgis B N and Hitchman M A 2000 Mineralogical Applications of Crystal Field Theory (New York: Wiley-VCH) p. 116

[57] Burns R G 1970 Mineralogical Applications of Crystal Field Theory (New York: Cambridge University Press) p. 17

[58] Choi S and Manthiram A 2002 J. Electrochem. Soc 149 A1157

[59] Hu E et al., 2016 Adv. Energy Mater. 61501662 ,

[60] Wang R, He X, He L, Wang F, Xiao R, Gu L, Li H and Chen L

2013 Adv. Energy Mater. 31358

[61] Gu L, Zhu C, Li H, Yu Y, Li C, Tsukimoto S, Maier J and Ikuhara Y 2013 J. Am. Chem. Soc. 1334661

[62] Sun Y K, Myung S T, Park B C, PrakashJ, Belharouak I and Amine K 2009 Nat. Mater. 8320

[63] Lu X, MacNeil D D and Dahn J R 2001 Electrochem. Solid-State Lett. 4 A191

[64] Thackeray M M, Johnson C S, Vaughey J T, Li N and Hackney S A 2006 J. Mater. Chem. 152257

[65] Mohanty D, Kalnaus S, Meisner R A, Rhodes K, Li J, Payzant E A, Wood III D L and Daniel C 2013 J. Power Sources 229239

[66] Zheng J, Gu M, Xiao J, Zuo P, Wang C and Zhang J G 2013 Nano Lett. 133824

[67] Sathiya M, Abakumov A M, Foix D, Rousse G, Ramesha K, Sauban'ere M, Doublet M L, Vezin H, Laisa C P, Prakash A S, Gonbeau D, VanTendeloo G and Tarascon J M 2015 Nat. Mater. 14230

[68] Gu M, Belharouak L, Zheng J, Wu H, Xiao J, Genc A, Amine K, Thevuthasan S, Baer D R, Zhang J G, Browning N D, Liu J and Wang C M 2013 ACS nano 7760

[69] Xu B, Fell C R, Chi M and Meng Y S 2011 Energy Environ. Sci. 42223

[70] Zheng J, Gu M, Xiao J, Polzin B J, Yan P, Chen X, Wang C and Zhang J G 2014 Chem. Mater. 266320 